\title{
Foraging mode and prey size spectra of suspension-feeding copepods and other zooplankton
}

\section{Kiørboe, Thomas}

Published in:

Marine Ecology Progress Series

Link to article, DOI:

$10.3354 /$ meps 11877

Publication date:

2016

Document Version

Publisher's PDF, also known as Version of record

Link back to DTU Orbit

Citation (APA):

Kiørboe, T. (2016). Foraging mode and prey size spectra of suspension-feeding copepods and other zooplankton. Marine Ecology Progress Series, 558, 15-20. https://doi.org/10.3354/meps11877

\section{General rights}

Copyright and moral rights for the publications made accessible in the public portal are retained by the authors and/or other copyright owners and it is a condition of accessing publications that users recognise and abide by the legal requirements associated with these rights.

- Users may download and print one copy of any publication from the public portal for the purpose of private study or research.

- You may not further distribute the material or use it for any profit-making activity or commercial gain

- You may freely distribute the URL identifying the publication in the public portal

If you believe that this document breaches copyright please contact us providing details, and we will remove access to the work immediately and investigate your claim. 


\title{
Foraging mode and prey size spectra of suspension-feeding copepods and other zooplankton
}

\author{
Thomas Kiørboe* \\ Centre for Ocean Life, DTU Aqua, Kavalergården 6, 2920 Charlottenlund, Denmark
}

\begin{abstract}
Prey size spectra of suspension-feeding zooplankton may be predicted from foraging mode and a mechanistic understanding of prey perception and capture. I examine this for suspension-feeding copepods where 2 foraging modes can be distinguished: ambush feeding and active (i.e. cruising and feeding-current) feeding. Prey perception mechanisms differ between the 2 foraging modes. I use simple arguments to predict that the ambush strategy targets larger prey and has a narrower prey size spectrum than the cruising and feeding-current feeding strategies. I compile data from the literature that confirm the prediction. I also make qualitative predictions of food size spectra in zooplankton with other prey perception mechanisms that accord with observations.
\end{abstract}

KEY WORDS: Prey perception mechanism - Prey capture mechanism - Pelagic tunicates · Heterotrophic flagellates $\cdot$ Dinoflagellates $\cdot$ Cladocerans

Resale or republication not permitted without written consent of the publisher

\section{INTRODUCTION}

The prey size spectrum is an important property of a consumer. It describes the optimum and size range of prey that can be eaten and thus defines the trophic position of the consumer (Boyce et al. 2015). It also helps define the competitive ability, puts constraints on spatio-temporal distributions, and impacts trophic transfer efficiencies (Barnes et al. 2010). The prey size spectrum is consequently a key parameter in many ecosystem models (Banas 2011). Overall, larger predators feed on larger prey when compared across taxa and over many orders of magnitude in size (Boyce et al. 2015), and this also applies to zooplankton (Kiørboe 2008). However, there can be large deviations from this overall pattern, both within and between taxa (Hansen et al. 1994, Fuchs \& Franks 2010), and attempts have consequently been made to examine patterns in these deviations and explore possible mechanistic underpinnings (Wirtz 2012). Compared to other zooplankton, pelagic copepods have a particularly large range of predator:prey size ratios (Fuchs \& Franks 2010), their foraging ecology is well studied, and they are the most abundant mesozooplankton group in the ocean. Thus, copepods are a particularly relevant group to study in this context.

Wirtz $(2012,2014)$ developed theories on the dependency of predator:prey size ratios on feeding mode in zooplankton and tested his ideas against observations. However, his classification of feeding modes appears inconsistent. The paper has no explicit definition of the feeding mode classification but distinguishes mainly between active feeding (cruising, ambushing; carnivory), passive feeding (feedingcurrent feeding; detritivory) and mixed feeding (herbivory). However, a cruiser, an ambusher, and a feeding-current feeder may all feed on phytoplankton, zooplankton and detritus, and it is unclear what a 'mixed feeder' is and so the groups appear ill defined. Boyce et al. (2015) adopted the foraging categories from Wirtz (2012), and the 2 papers then collect literature information to demonstrate that the prey:predator size ratio is largest for the passive feeders and smallest for the active feeders, with the mixed group in between. However, neither of the papers define how they assign a feeding mode to individual species, although Wirtz (2012) classified broad taxonomic 
groups to feeding strategy (e.g. dinoflagellates as 'active', rotifers as 'passive' feeders, and flagellates as 'mixed') without justification or arguments.

Here, I use the simple classification and characterization of feeding strategies defined by Kiørboe (2011): (1) ambush feeders are motionless and wait for motile prey to pass within the sensory reach or directly collide with the consumer; (2) feeding-current feeders hover while generating a feeding current and harvest prey that arrives with the feeding current; and (3) cruise feeders capture prey that they encounter as they cruise through the water. The separation between cruise and feeding-current feeding is not distinct; most zooplankters both generate a feeding current and cruise through the water, and so here I distinguish only between ambush feeders and active feeders (cruise and feeding-current feeders). I apply these categories to pelagic copepods, for which the best data are available. Because the 2 types of feeders perceive their prey differently (Gonçalves \& Kiørboe 2015) and target somewhat different prey (an ambush feeder can only encounter motile prey), I ask whether prey size spectra vary with feeding mode.

\section{THEORETICAL CONSIDERATIONS}

The prey size spectrum of a consumer is the product of the functions that describe how prey encounter rate increases and capture and ingestion success decreases with increasing prey size. These functions determine the ascending and descending parts of the prey size spectrum. In the following I discuss these functions for the 2 foraging modes in copepods, ignoring that other factors than size may influence encounter rate and capture success.

The increase in encounter rate with prey size is likely to differ between ambush and active feeders, since they perceive their prey differently. Ambush feeders perceive their prey through the fluid disturbance that the prey makes. Describing the prey as a 'stresslet', i.e. an often used idealized fluid mechanical model of a self-propelled organism swimming at low Reynolds numbers, yields that the detection distance, $R$, to the prey is $R \propto a\left(u / s^{*}\right)^{0.5}$, where $a$ and $u$ are the radius and velocity of the prey, respectively, and $s^{*}$ is the signal strength required to elicit an attack response (Svensen \& Kiørboe 2000, Jiang \& Paffenhöfer 2008). The encounter rate then scales with $R^{2} u \propto a^{2} u^{2} / s^{*} \propto a^{4}$, that is, it rapidly increases with increasing prey size. Prey smaller than a certain threshold, ultimately prey that swim slower than $s^{*}$, cannot be perceived.
Active feeders may perceive motile prey the same way, but may in addition (and mainly) encounter nonmotile prey, which are perceived differently. Most observations suggest that the prey has to touch or nearly touch the setae of the feeding appendages to elicit a capture reaction (Gonçalves \& Kiørboe 2015). The exact detection mechanism remains controversial, but there seems to be consensus that observations demonstrate that prey is detected only when within a few prey radii (Kiørboe et al. 2016, Paffenhöfer \& Jiang 2016), and a simple fluid mechanical model of Visser (2001) accords with observations in suggesting $R \propto$ a (Gonçalves \& Kiørboe 2015). If the feeding current or swimming velocity is $V$, the clearance rate scales with $R^{2} v \propto a^{3}$. This may not be entirely correct, since small prey close to the detection limit are likely detected with lower probability than larger prey, but that probability presumably saturates quickly with size. In addition, prey that are too small to be detected may still be captured in a passive mode, albeit at a relatively low rate (Price et al. 1983, Vanderploeg et al. 1988). Thus, the considerations suggest that prey sizes smaller than the detection limit are included in the size spectrum and that the increase in encounter rate with increasing prey size is slower in active feeders than in ambush feeders. Everything else being equal, this would push the ascending part of the prey size spectrum towards larger prey for ambush compared to active feeders.

The descending part of the size spectrum, determined by pursuit and capture success of encountered (detected) prey, may also differ with feeding mode. In both types, handling difficulties (Fig. 1A and Video S1 in the Supplement at www.int-res.com/articles/suppl/ m558p015_supp/) and gape width constrain the upper limit of the prey size spectrum, but motile prey may in addition be able to escape (Jakobsen 2001) (Fig. 1B and Video S2), and larger and faster prey likely escape more easily than smaller and slower ones. This would push the descending part of the prey size spectrum towards smaller prey for ambush feeders compared to active feeders.

Overall, the theoretical considerations suggest the prey size spectrum to be narrower and shifted towards larger prey for ambush feeders than for active feeders.

\section{MATERIALS AND METHODS}

There are previous data compilations on prey size spectra in copepods and other zooplankton, but they define the prey size spectrum and the optimum prey 

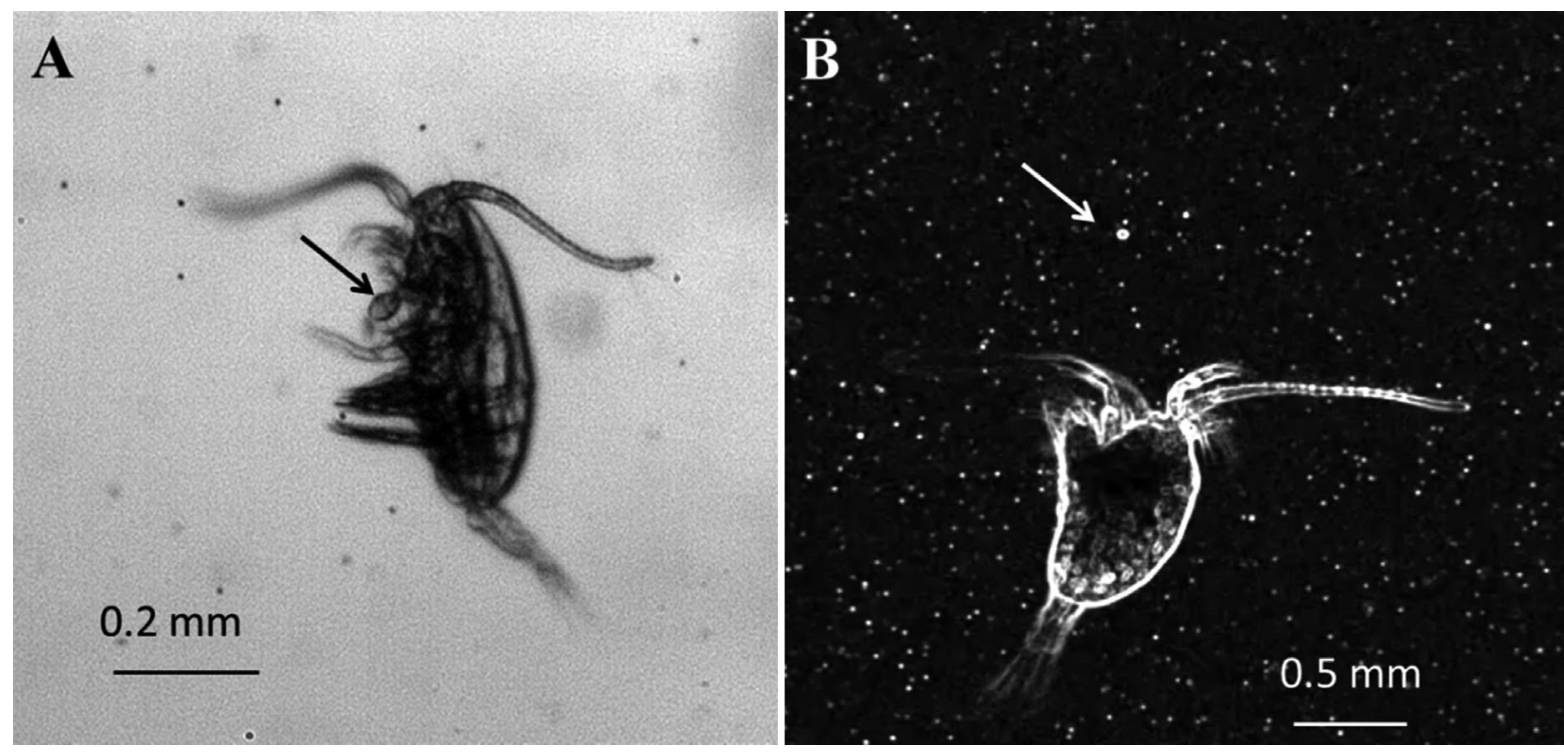

Fig. 1. High-speed video images showing feeding copepods and their prey (arrows). (A) The copepod Paracalanus parvus handling a large dinoflagellate (Akashiwo sanguinea). (B) The ciliate Mesodinium rubrum has been entrained in the feeding current of Temora longicornis, and escapes by powerful jumps away from the copepod. See Videos S1 \& S2 in the Supplement at www.int-res.com/articles/suppl/m558p015_supp/

size differently (Hansen et al. 1994, Fuchs \& Franks 2010, Wirtz 2012). The prey size spectrum is best described by the dependency of the maximum clearance rate on prey size (Hansen et al. 1994), and I adopt this description here. The maximum clearance rate is the clearance rate at low prey concentration, where processing (digestion) of prey is not limiting ingestion. It is estimated as the initial slope of the functional response in ingestion rate to prey concentration for a Holling type II response, or as the peak clearance rate for a Holling type III response. Expanding on the database of Kiørboe \& Hirst (2014), I compiled experimental observations of functional responses in marine suspension-feeding copepods offered a variety of prey sizes. For each prey size I computed the maximum clearance rate from fits of functional type functions to the data, all as explained in Kiørboe \& Hirst (2014) and largely following Hansen et al. (1994). All prey sizes and copepod sizes were converted to carbon masses using information in the original papers and standard conversion factors (Menden-Deuer \& Lessard 2000, Kiørboe 2013). To facilitate comparisons, all clearance rates were converted to a temperature of $15^{\circ} \mathrm{C}$ assuming a $Q_{10}$ of 2.8 as in Hansen et al. (1997). In each data set, the optimum prey size was defined as the prey size yielding the highest clearance rate. In many cases, the highest clearance rate was found for the largest prey tested, thus providing a minimum estimate of the optimum prey size. In total, I compiled 271 estimates of maximum clearance rates (78 and 193 for ambush and active feeders, respectively), and 97 estimates of optimum prey size (23 and 74, respectively). For obvious reasons the database is biased towards adult copepods of the most-studied species. All data are shown in Table S1 in the Supplement.

\section{RESULTS}

The optimum prey size has a more narrow distribution and is shifted towards larger prey for ambush compared to actively feeding copepods, as expected (Fig 2A). The Gaussian fits suggest optimum prey: predator sizes differing significantly (Welch 2-sample $t$-test, $\mathrm{p}=0.0002208$ ) by a little more than an order of magnitude between active and passive feeders, with means of $10^{-3.7}$ and $10^{-2.4}$, respectively, and a factor of $\sim 7$ higher variance for the active compared to the passive feeders. When all estimates of maximum clearance rates are plotted together, a similar but much less clear pattern emerges (Fig. 2B). Most observations of clearance rates have been made with smaller than optimally sized prey, and so most observations fall on the ascending part of the size spectrum. Therefore, some of the difference in Fig. 2A reflects experimental choices of prey sizes. Nevertheless, the difference in optimum prey size persists 

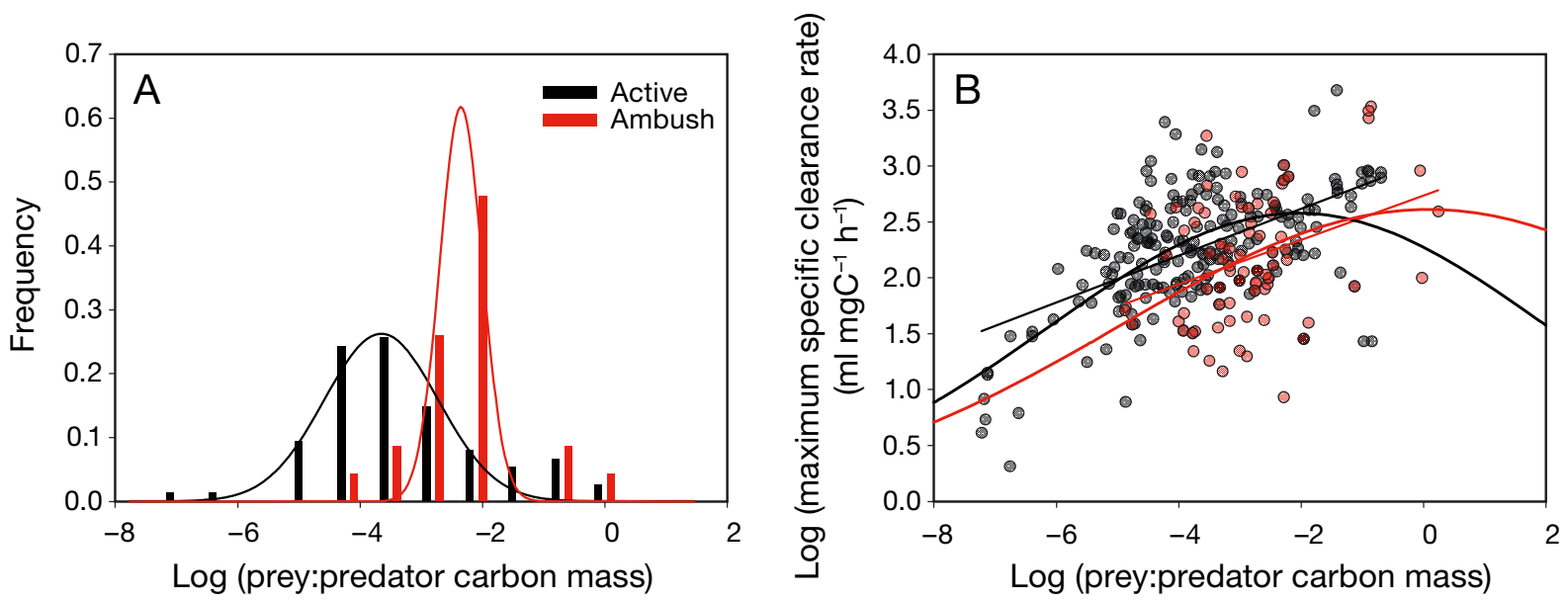

Fig. 2. Frequency distributions of (A) optimum prey:predator size ratios for ambush and active feeding pelagic copepods and (B) all maximum clearance rates plotted against prey:predator body carbon mass ratios for ambush-feeding and active-feeding copepods. Gaussian distributions and linear regressions were fitted to the data. The mean and variance of the Gaussian fits are -3.66 and 0.86 for the active feeders, respectively and -2.35 and 0.12 for the passive feeders, respectively, in panel (A). The linear regressions in panel (B) are for ambush feeders:log(specific clearance rate) $=2.73+0.20 \log$ (predator:prey ratio); active feeders: $\log ($ specific clearance rate $)=3.04+0.21 \log$ (predator:prey ratio). The slopes do not differ significantly, while the intercepts do $\left(p=7 \times 10^{-5}\right)$, and the difference in intercepts corresponds to an order of magnitude larger optimum prey size for ambush feeders compared to active feeders. The Gaussian fits in panel (B) are mean $=2.04$ and variance $=16$ for active feeders, and 0.08 and 25 , respectively, for passive feeders

and is statistically significant, e.g. as revealed by comparison of the elevations in the 2 linear regressions that predict relative prey sizes larger by a factor of 10 for ambushers compared to active feeders (comparison of linear regression by ANOVA, $\mathrm{p}<0.0001$ ), consistent with the above estimate.

\section{DISCUSSION}

The classification of foraging modes used here applies to zooplankton in general (Kiørboe 2011), but the results for copepods cannot be generalized. However, the idea that the prey size spectrum depends on prey perception and capture mechanism applies more generally and may help explain differences in prey size spectra as reported for several groups of marine zooplankton, including heterotrophic nanoflagellates, dinoflagellates, cladocerans, and pelagic tunicates (Hansen et al. 1994, Fuchs \& Franks 2010). It is important to note, however, that foraging mode and prey perception and capture mechanisms are not closely correlated, particularly when these mechanistic explanations of prey size spectra are extended beyond copepods. Thus, active feeders that generate a feeding current may be true filter feeders (e.g. tunicates), the feeding current may be a scanning current from where prey are perceived and captured individually (e.g. copepods and rotifers), or the prey arriving in the feeding current may simply be intercepted by the (cell)body ('interception feeders', e.g. some heterotrophic flagellates; Fenchel 1982). Similarly, ambush feeders may remotely perceive and capture individual prey (e.g. copepods, chaeotognaths; Kiørboe et al. 2009), or motile prey may simply bump into the consumer without any pre-capture response of the consumer ('diffusion feeders', e.g. helioflagellate; Fenchel 1982).

Individual perception of prey requires that the prey exceeds a certain threshold size to be detected. The lower size limits for chemical and fluid mechanical detection in the plankton is in the range of 1-10 $\mu \mathrm{m}$ due to the physics of signal generation and transmission (Kiørboe 2011), whereas visual detection which is rare and inefficient in zooplanktonrequires much larger prey (Martens et al. 2015). Thus, millimetre-sized cladocerans and copepods of the genus Coryceaus that hunt prey visually typically feed on prey near their own size (Landry et al. 1985), whereas copepods using fluid-mechanical signals have much lower size thresholds of around 2-10 $\mu \mathrm{m}$. Because the lower threshold for chemical and fluid mechanical detection is independent of the size of the consumer, unicellular dinoflagellates that perceive individual prey from chemical cues (Buskey 1997) feed on prey that are large relative to themselves (Hansen et al. 1994)

In contrast, for active-feeding zooplankton that concentrate prey automatically by some filtering process, the lower size threshold is given by the filter 
dimensions, which has no theoretical lower size limit. Here the constraint is the pressure drop required to push water through the filter: the finer the mesh, the larger the amount of prey available in a unit volume of ambient water, but the lower the clearance rate for a set force to produce the pressure drop; the optimum filter size is governed by this tradeoff. The archetypical planktonic filter feeders in the ocean are unicellular choanoflagellates and pelagic tunicates; both groups retain sub-micron sized particles (Andersen 1988, Sutherland et al. 2010). The upper size limit is ultimately governed by the size of the consumer, and the millimetre-sized and larger tunicates (salps, doliolids, appendicularians) consequently have by far the widest food size spectra reported among zooplankton (Fuchs \& Franks 2010). The availability of larger prey to larger filter feeders relaxes the need of a very fine-meshed filter, and would thus suggest that larger tunicates have coarser meshes and larger minimum prey sizes than smaller ones. This prediction is confirmed by observations (Bone et al. 2003, Sutherland et al. 2010).

Finally, heterotrophic 'interception-' and 'diffusionfeeding' protists depend on advected or 'diffusing' (motile) prey directly intercepting the cell body without any a priori sensing (Fenchel 1982). Simple fluid physics arguments predict that encounter rates scale with prey size and consumer size, respectively, for these 2 feeding modes (Kiørboe 2011), and, hence, that specific clearance rates scale with consumer size (radius) to power -3 and -2 , respectively, and clearance rates are most efficient for small consumers feeding on large prey. This implies large prey: predator size ratios and also narrow prey size spectra, since the upper prey size is again ultimately limited by consumer size. This is exactly as reported by Fuchs \& Franks (2010).

In conclusion, foraging mode and prey perception and capture mechanisms determine diets (not vice versa) and prey size spectra, and a correct mechanistic understanding of these processes allows predictions - or at least explanations - of prey size spectra in zooplankton.

Acknowledgements. The Centre for Ocean Life is supported by the Villum Foundation.

\section{LITERATURE CITED}

Andersen P (1988) Functional biology of the choanoflagellate Diaphanoeca grandis Ellis. Mar Microb Food Webs 3:35-49

Banas NS (2011) Adding complex trophic interactions to a size-spectral plankton model: emergent diversity patterns and limits on predictability. Ecol Model 222: 2663-2675

Barnes C, Maxwell D, Reuman D, Jennings S (2010) Global patterns in predator-prey size relationships reveal size dependency of trophic transfer efficiency. Ecology 91: 222-232

Bone Q, Carre C, Chang P (2003) Tunicate feeding filters. J Mar Biol Assoc UK 83:907-919

> Boyce DG, Frank KT, Leggett WC (2015) From mice to elephants: overturning the 'one size fits all' paradigm in marine plankton food chains. Ecol Lett 18:504-515

Buskey EJ (1997) Behavioral components of feeding selectivity of the heterotrophic dineflagellate Protoperidinium pellucidum. Mar Ecol Prog Ser 153:77-89

Fenchel T (1982) Ecology of heterotrophic microflagellates. I. Some important forms and their functional morphology. Mar Ecol Prog Ser 8:211-223

Fuchs HL, Franks PJS (2010) Plankton community properties determined by nutrients and size-selective feeding. Mar Ecol Prog Ser 413:1-15

> Gonçalves RJ, Kiørboe T (2015) Perceiving the algae: how feeding-current feeding copepods detect their nonmotile prey. Limnol Oceanogr 60:1286-1297

> Hansen B, Bjørnsen PK, Hansen PJ (1994) The size ratio between planktonic predators and their prey. Limnol Oceanogr 39:395-403

Hansen PJ, Bjørnsen PK, Hansen B (1997) Zooplankton grazing and growth: scaling within the $2-2000 \mu \mathrm{m}$ body size range. Limnol Oceanogr 42:687-704

Jakobsen HH (2001) Escape response of planktonic protists to fluid mechanical signals. Mar Ecol Prog Ser 214: $67-78$

Jiang H, Paffenhöfer G (2008) Hydrodynamic signal perception by the copepod Oithona plumifera. Mar Ecol Prog Ser 373:37-52

Kiørboe T (2008) A mechanistic approach to plankton ecology. Princeton University Press, Princeton, NJ

Kiørboe T, Andersen A, Langlois VJ, Jakobsen HH, Bohr T (2009) Mechanisms and feasibility of prey capture in ambush feeding zooplankton. Proc Natl Acad Sci USA 106:12394-12399

> Kiørboe T (2011) How zooplankton feed: mechanisms, traits and trade-offs. Biol Rev Camb Philos Soc 86:311-339

> Kiørboe T (2013) Zooplankton body composition. Limnol Oceanogr 58:1843-1850

Kiørboe T, Hirst AG (2014) Shifts in mass scaling of respiration, feeding, and growth rates across life-form transitions in marine pelagic organisms. Am Nat 183:E118-E130

> Kiørboe T, Gonçalves RJ, Couespel D, Someren Gréve H van, Saiz E, Tiselius P (2016) Reply to Comment: prey perception in feeding-current feeding copepods. Limnol Oceanogr 61:1169-1171

Landry MR, Lehner-Fournier JM, Fagerness VL (1985) Predatory feeding behavior of the marine cyclopoid copepod Corycaeus anglicus. Mar Biol 85:163-169

Martens EA, Wadhwa N, Jacobsen NS, Lindemann C, Andersen KH, Visser A (2015) Size structures sensory hierarchy in ocean life. Proc R Soc B 282:20151346

> Menden-Deuer S, Lessard EJ (2000) Carbon to volume relationships for dinoflagellates, diatoms, and other protist plankton. Limnol Oceanogr 45:569-579

Paffenhöfer GA, Jiang H (2016) On phytoplankton perception by calanoid copepods. Limnol Oceanogr 61:1161-1168

Price HJ, Paffenhöfer GA, Strickler JR (1983) Modes of cell 
capture in calanoid copepods. Limnol Oceanogr 28: 116-123

Sutherland KR, Madin LP, Stocker R (2010) Filtration of submicrometer particles by pelagic tunicates. Proc Natl Acad Sci USA 107:15129-15134

Svensen C, Kiørboe T (2000) Remote prey detection in Oithona similis: hydromechanical versus chemical cues. J Plankton Res 22:1155-1166

Vanderploeg HA, Paffenhofer GA, Liebig JR (1988) Diaptomus vs. net phytoplankton: effects of algal size and morphology on selectivity of a behaviorally flexible, omnivo-

Editorial responsibility: Myron Peck,

Hamburg, Germany rous copepod. Bull Mar Sci 43:377-394

Visser A (2001) Hydromechanical signals in the plankton. Mar Ecol Prog Ser 222:1-24

Wirtz K (2012) Who is eating whom? Morphology and feeding type determine the size relation between planktonic predators and their ideal prey. Mar Ecol Prog Ser 445: $1-12$

- Wirtz K (2014) A biomechanical and optimality-based derivation of prey-size dependencies in planktonic prey selection and ingestion rates. Mar Ecol Prog Ser 507: 81-94

Submitted: April 29, 2016; Accepted: August 18, 2016 Proofs received from author(s): September 27, 2016 